\title{
A CONCILIAÇÃO NAS DEMANDAS DO PODER PÚBLICO COMO INSTRUMENTO DE PACIFICAÇÃO SOCIAL E EFICIÊNCIA NA ADMINISTRAÇÃO
}

\author{
CONCILIATION IN PUBLIC POWER DEMANDS AS \\ AN INSTRUMENT OF SOCIAL PACIFICATION AND \\ EFFICIENCY IN THE ADMINISTRATION
}

\author{
Fernando Machado de Souza ${ }^{11}$ \\ Joe Graeff Filho ${ }^{22}$ \\ Recebido em: 17/01/2017 \\ Aprovado em: 09/08/2017
}

\section{RESUMO}

O presente artigo aborda dois importantes aspectos justificadores da conciliação, nas demandas que envolvem o Poder Público, sendo a pacificação social e o reflexo desta na eficiência da Administração Pública. Através da entrada em vigor do Código de Processo Civil de 2015, que inseriu expressa-

\footnotetext{
${ }^{1}$ Doutorando em Direito Constitucional pela Instituição Toledo de Ensino - ITE. Mestre em Direito Processual Civil pela Universidade Paranaense UNIPAR (2015). Especialista em Direito Administrativo e em Direito Previdenciário (2013). Graduado em Direito pela Universidade Estadual de Mato Grosso do Sul (2011). Professor do Curso de Pós-Graduação Lato Sensu em Direitos Difusos e Coletivos da Universidade Estadual de Mato Grosso do Sul (UEMS). Professor de Direito Administrativo e Direito Internacional no Centro Universitário da Grande Dourados (UNIGRAN). Chefe da Assessoria Jurídica da Universidade Estadual de Mato Grosso do Sul (UEMS).

${ }^{2}$ Possui graduação Ciências Jurídicas pelo Centro Universitário da Grande Dourados-UNIGRAN (1998), com Especialização em Direito das Obrigações (1999), Atualmente é Coordenador do Curso de Direito, professor titular nos cursos de Direito (Direito Penal) e Engenharia Civil (Direito e Legislação em Engenharia Civil ) do Centro Universitário da Grande Dourados e titular de Escritório de Advocacia. Tem experiência na área de Direito, com ênfase em Direito Penal. É Mestre em Desenvolvimento Local da UCDB - Universidade Católica Dom Bosco. Doutorando regular do programa em Desenvolvimento Local da UCDB.
} 
mente em seu texto o princípio da solução consensual dos conflitos, busca-se a aplicação dos métodos consensuais à Administração Pública, por ser esta individualmente, a maior litigante do Poder Judiciário.

\section{PALAVRAS-CHAVE}

Conciliação. Pacificação Social. Eficiência. Solução Consensual.

\section{ABSTRACT}

The present article addresses two important justificatory aspects of conciliation, in the demands that involve the Public Power, being the social pacification and the reflection of this in the efficiency of the Public Administration. Through the entry into force of the Code of Civil Procedure of 2015, which expressly inserted in its text the principle of the consensual solution of conflicts, it is sought the application of the consensual methods to the Public Administration, since it is individually, the largest litigant of the Judiciary.

\section{KEYWORDS}

Conciliation. Social Pacification. Efficiency. Consensus Solution. 


\section{Introdução}

A conciliação como forma de solução de conflitos ganhou destaque no direito processual brasileiro, sobretudo a partir da Lei do Juizado Especial (Lei 9.099/95). Justo considerar, que o êxito demonstrado nas quase duas décadas de aplicação no rito sumaríssimo, serviu de inspiração para a alteração procedimental instituída pelo Código de Processo Civil atual, que, além da obrigatoriedade na realização da audiência de conciliação ou mediação, acertadamente estitpulou que a mês a fosse realizada antes do início do prazo para contestação, seguindo assim a lição do experiente Juizado.

Outrossim, para que a conciliação, assim como a mediação e a arbitragem, possa representar um efetivo mecanismo de solução de conflitos, em termos quantitativos, deverá ser utilizada pelo Poder Público, pois o Estado é o maior litigante do Poder Judiciário.

Conforme o relatório intitulado 100 Maiores Litigantes do Poder Judiciário ${ }^{3}$, elaborado pelo Conselho Naconal de Justiça com intuito de consolidar informações quantitativas e identificar os setores que mais utilizam do Poder Judiciário, com vistas a suscitar o debate sobre o que pode ser feito para reduzir a excessiva litigância no Brasil, onde juntos, os três Setores Públicos (Federal, Estadual e Municipal) respondem por $22,77 \%$ do total de ingresso de novas demandas judiciais, o que significa que aproximadamente um quarto da utilização da estrutura do Poder Judiciário é destinada para o próprio Estado, que a utiliza compulsoriamente para o tratamento de conflitos que, não raro, poderiam ser solucionados por outros meios, que não necessariamente a sentença de mérito.

Nesse sentido, o objetivo deste artigo é fundamentar a utilização da conciliação nas demandas que envolvem o próprio Estado, sob o aspecto da pacificação social e do ganho em eficiência decorrente da economia de recursos financeiros, decorrente da construção de uma solução por ambas as partes.

\section{Princípio da Solução Pacífica dos Conflitos}

Dentre os principais compromissos assumidos pelo Código de Processo

\footnotetext{
${ }^{3}$ Disponível em http://www.cnj.jus.br/noticias/cnj/59351-orgaos-federais-e-estaduais-lideram-100-maiores-litigantes-da-justica, acesso em 10 de janeiro de 2017
} 
Civil de 2015, está a solução pacífica dos litígios, tendo como uma de suas características a viabilização de significativa abertura para a autonomia privada das partes. (MARINONI, 2015, p. 97).

Para Medina (2015, p. 29), o recente Código amplia a acepção de acesso à Justiça, para compreender não apenas as "soluções decisionais", mas também os meios consensuais, como a mediação e a conciliação. Esses meios, antes tidos como alternativos, passam a ser estimulados pelo Novo Código de Processo Civil.

O Art. $3^{\circ}$ do Código de Processo Civil possui dupla dimensão na persecussão da solução pacífica dos conflitos: no $\$ 2^{\circ}$ incumbe ao Estado a tarefa de buscar, sempre que possível, a resolução consensual das demandas, enquanto no $\S 3^{\circ}$, atribui a responsabilidade pelo fomento da cultura de pacificação dos atores do processo em relação às partes .

Os problemas sociais, como alerta Medina (2013, p. 47), mostram cada vez mais sofisticados e variados, o que impõe ao órgão jurisdicional, não só a correta compreensão dos novos métodos observados na elaboração das leis, mas também sua inserção na realidade social. Nessa linha, o raciocínio quanto à solução dos conflitos segue a mesma vertente, exigindo-se do julgador uma nova interpretação dos métodos de solução dos conflitos.

Com a massificação dos litígios e a judicialização de direitos até então excluídos de apreciação judicial (direitos difusos, coletivos e individuais homogêneos), é necessária a superação do conceito tradicional da lide, na busca da efetividade processual, assim definida por Jonatas Luiz Moreira de Paula (1999. p. 100), ao ensinar que jurisdição efetiva é aquela que realiza concretamente os anseios dos litigantes, sobretudo ao vitorioso da demanda. Para tanto, é preciso consorciar dois binômios: efetividade e satisfação.

A partir do referido dispositivo, a conciliação, a mediação e qualquer outra forma de convenção voluntária, deverão ser estimuladas pelos juízes, advogados, defensores públicos e membros do Ministério Público, independentemente da fase processual, o que nas palavras de Medina (2015, p. 42) significa que a autocomposição deve ser buscada de forma incidental em qualquer fase processual.

Outros dispositivos contidos na nova Lei Processual permitem visualizar a expansão do instituto de resolução consensual, como o Art. 139, V, que frisa ao juiz, o dever de promoção da autocomposição a qualquer tempo, preferencial- 
mente com o auxílio de conciliadores e mediadores judiciais .

Os conciliadores e mediadores judiciais integrarão os centros judiciários de solução consensual dos conflitos, que serão responsáveis pela realização de sessões e audiências de conciliação e mediação e pelo desenvolvimento de programas destinados a incentivar e auxiliar a autocomposição, conforme determina o Art. 165 do Código de Processo Civil de 2015. Como bem lembra Marinoni (2015, p. 230), todos os tribunais devem, obrigatoriamente, independentemente de suas especificidades organizacionais, criar centros de resolução pacífica dos conflitos como fomento à cultura da pacificação.

O Conselho Nacional de Justiça - CNJ, por meio da Resolução 125, de 29 de novembro de 2010, instituiu a Política Judiciária Nacional de tratamento dos conflitos de interesses, tendente a assegurar a todos o direito à solução dos conflitos por meios adequados à sua natureza e peculiaridade. Dentre os objetivos primordiais da mencionada Política estão a disseminação de uma cultura de solução alternativa, substituindo a sentença de mérito pela resolução consensual, implementando mecanismos e aperfeiçoando os já existentes, de autocomposição entre as partes.

A Resolução 125/2010 distribui no âmbito do Poder Judiciário, a responsabilidade pela implantação da Política Nacional de tratamento dos conflitos, de modo que compete ao próprio Conselho Nacional de Justiça, organizar programa com o objetivo de promover ações de incentivo à autocomposição de litígios e à pacificação social por meio da conciliação e da mediação, conforme Art. $4^{\circ}$ da Resolução .

Aos tribunais competem a criação de Núcleos Permanentes de Métodos Consensuais de Solução de Conflitos, compostos por magistrados da ativa ou aposentados e servidores, preferencialmente atuantes na área, que deverão desenvolver a Política Judiciária de tratamento adequado dos conflitos de interesses, por meio de, dentre outras ações, proceder a instalação de Centros Judiciários de Solução de Conflitos e Cidadania, que concentrarão a realização das sessões de conciliação e mediação que estejam a cargo de conciliadores e mediadores, dos órgãos por eles abrangidos.

Nos termos do Art. $8^{\circ}$ da resolução 125/2010, dentro das atividades incumbidas ao Poder Judiciário: 
Art. $8^{\circ}$ Para atender aos Juízos, Juizados ou Varas com competência nas áreas cível, fazendária, previdenciária, de família ou dos Juizados Especiais Cíveis, Criminais e Fazendários, os Tribunais deverão criar os Centros Judiciários de Solução de Conflitos e Cidadania ("Centros"), unidades do Poder Judiciário, preferencialmente, responsáveis pela realização das sessões e audiências de conciliação e mediação que estejam a cargo de conciliadores e mediadores, bem como pelo atendimento e orientação ao cidadão.

No estado de Mato Grosso do Sul, o Núcleo Permanente de Métodos Consensuais de Solução de Conflitos foi criado pelo Provimento n. 230, de 30 de março de 2011, revogado pelo Provimento-CSM n. 340, de 11 de março de 2015, que alterou o funcionamento do mesmo. Em São Paulo, a criação dos Centros Judiciários de Solução de Conflitos e Cidadania (denominados de Centros), decorreu do Provimento 1.892/2011.

No estado de São Paulo, onde estatísticas são disponibilizadas pelo Tribunal de Justiça - TJSP , em 2014 foram realizadas 25.578 audiências de conciliação, durante a Semana Nacional de Conciliação, sendo homologados 13.056 acordos (pouco mais de 50\% de êxito).

Os números demonstram um crescimento no índice de homologação de acordos, pois em 2007 foram realizadas 7.166 audiências de conciliação, em primeira instância, das quais foram solucionadas 2.901, o que representa cerca de um terço do índice de aproveitamento.

De acordo com os esses dados do Tribunal de Justiça de São Paulo, é possível aferir que após a implantação das diretrizes contidas na resolução 125/2010, houve um crescimento proporcional do índice de homologação de acordos, demonstrando uma sensível evolução qualitativa da política. Em 2010 foram realizadas 17.847 audiências, sendo obtida a conciliação em 6.348 destas, enquanto em 2013 (dois anos após a implantação dos Centros Judiciários de Solução de Conflitos e Cidadania) foram realizadas 17.214 audiências, com 7.782 acordos homologados.

\section{Conciliação}

Prevista no art. 165 do Código de Processo Civil de 2015, a conciliação integra a política de solução consensual incentivada pela nova lei, por serem parte da estratégia a ser desenvolvida pelos centros de resolução consensual de con- 
flitos, que deverão ser implantados pelos tribunais, sem prejuízo do desenvolvimento de programas destinados a auxiliar, orientar e estimular a autocomposição.

Conforme destacado anteriormente, o Código de Processo Civil inovou ao prever a obrigatoriedade da audiência especificamente para a tentativa de conciliação (ou mediação), antes do início do prazo de constestação para o réu (art. 334,CPC). A única ressalva reside na hipótese de ambos manifestarem expressamente o desisteresse pela audiência, hipótese em que a mesma será dispensada pelo magistrado, ou quando não se admitir autocomposição (art. 334, $\S 4^{\circ}$ ).

A conciliação é recomendada pelo art. $165, \S 2^{\circ}$, para os casos em que, preferencialmente, não houver vínculo anterior entre os litigantes, com possibilidade de participação ativa do conciliador na propositura de soluções alternativas, sem qualquer tipo de constrangimento ou intimidação para que as partes conciliem.

Mancuso (2014, p. 249) lembra que na conciliação há uma alteração na clássica das atribuições do juiz, que passa de destinatário na prova para uma postura mais pró-ativa, atuando como um vetor de possível solução negociada da lide.

A conciliação, além do destaque obtido no texto da lei processual, integra a Política Judiciária Nacional de tratamento dos conflitos de interesses, desenvolvida pelo Conselho Nacional de Justiça. Convém ressaltar que esta entidade tem voltado sua atuação à solução dos conflitos por meios consensuais, adequados à sua natureza e peculiaridade.

A Política Judiciária Nacional foi regulamentada pelo Conselho Nacional de Justiça na Resolução n ${ }^{\circ} 125$, de 29 de novembro de 2010, e vem sendo incentivada em campanhas como a da Semana Nacional de Conciliação, na qual processos que tenham a possibilidade de acordo são selecionados de ofício pelos Tribunais, ou mediante solicitação dos envolvidos, para tentativa de conciliação.

O esforço institucional pela valorização decorre do preconceito contra os métodos alternativos, que dentro da dogmática processual tradicional, superestima a sentença como o provimento jurisdicional nobre, em detrimento de outras formas de solução, como se estas não compusessem a atividade processual. A esse respeito, Dinamarco (1986, p. 42) ressalta há muito, que a conciliação constitui fase regular do processo, ao dispor que: No processo das pequenas causas, a conciliação é atividade que se insere entre as atividades processuais e tem 
natureza processual também, não sendo correto afirmar que venha antes do processo.

Importante destacar que, além do Juiz, poderá este papel ser desempenhado pelo conciliador, auxiliar da Justiça, tentará, de acordo com sua competência, auxiliar as partes propondo soluções alternativas ou mesmo direcionando o diálogo entres estas.

Reitera-se, que de regra, que a conciliação deve versar sobre direitos patrimoniais disponíveis, a respeito do que foi tratado no que concerne à transação, acompanhando o disposto no art. 841 do Código Civil.

Caso as partes cheguem a acordo, que como dito acima, decorre de concessões recíprocas, transação, ou por abandono da pretensão ou da resistência (renúncia e reconhecimento do pedido, respectivamente), será seu conteúdo lavrado em termo, que disporá de força de título executivo . (MOREIRA, 2008, p. 81-82)

\section{A Pacificação Social}

A denominada pacificação social tem tomado lugar de destaque nas reflexões jurídicas contemporâneas, justificada pelas discussões do escopo da Jurisdição, que no plano do dever-ser, representa o instrumento de resolução dos litígios advindos da sociedade. Contudo, as mazelas do Poder Judiciário no plano do ser, transformaram a pretensa solução, na própria origem dos problemas. Seja em decorrência da Justiça tardia (que sequer é considerada Justiça), dos altos custos que envolvem as demandas, ou ainda da sensação de perpetuidade das relações jurídicas, motivadas pela interminável escalada dos degraus da jurisdição, o processo atual tem fracassado continuamente no escopo de pacificação social.

A preocupação com o escopo pacificador da jurisdição vem de longa data:

A angústia da via cara e complicada de acesso aos órgãos do Poder Judiciário, mais as prolongadas esperas pelo produto acabado dos demorados processos que esta celebra formalmente, constituem fatores que, se não os agravam, impedem que o Estado possa eficazmente eliminar os conflitos que, no convívio social, conduzem à infelicidade pessoal de cada um e a atitudes de perigosa desconfiança em face das instituições estatais e descrença dos valores em sociedade. (DINAMARCO, 1986, p. 1). 
Nesse aspecto, o processo civil, necessariamente tem que amoldar-se às necessidades da sociedade, sobretudo na fase atual de implantação de nova ordem processual, uma vez que a sociedade não é estática, e do seu dinamismo, afirma Paula (2014, p. 204), "novas regras e valores sociais são construídos". Candido Rangel Dinamarco (2016, p. 20), afirma que o principal escopo da Jurisdição é o social, que consiste na pacificação de pessoas mediante a eliminação de conflitos com justiça.

Para José Miguel Garcia Medina (2016, p. 74), o processo, deve, à luz do Código atual, representar o lugar e o momento em que se compreende o problema social e se constrói o sentido da norma. Com isso, será possível resolver a lide, alcançando-se a paz jurídica.

Como lembra Marinoni (2015, p.93), o Estado Constitucional deve adotar "condutas concretizadoras do ideal de protetividade" para com os jurisdicionados, instituindo um sistema de segurança jurídica e certeza de prestação jurisdicional.

É cediço que, as políticas de acesso à Justiça das duas últimas décadas (Juizados Especiais, ampliação da estrutura judiciária, jus postulandi, acesso à informação), permitiram considerável liberação da litigiosidade contida na sociedade. O cidadão comum, antes refratário aos balcões do Judiciário, atualmente o utiliza com a frequência de consumo de um bem perecível. Não raro, canaliza-se por meio do Judiciário uma série de frustrações advindas da má-prestação de serviços básicos (telefonia, transportes), decorrentes da frágil regulação promovida pelas agências supostamente reguladoras, ou ainda pelo uso predatório de grandes grupos econômicos, que alicerçados em poder econômico ou político (quando não, ambos), utilizam da sistemática processual como meio de potencializar lucros, como é o caso de instituições financeiras, convergindo para o Poder Judiciário as crescentes angústias da complexa vida contemporânea.

Corroborando o entendimento acerca do escopo social da Jurisdição, determina Jônatas Luiz Moreira de Paula (1999, p. 100) que a Jurisdição deverá ser satisfativa, posto que não deve restringir apenas a uma declaração do Estado, mas concretamente realizar a pretensão dos litigantes, onde a tradução econômica da pretensão atendida pela jurisdição significa alcançar seus fins sociais.

Nesse passo, ao se confirmar que o escopo social da Jurisdição se resume à pacificação social por meio da eliminação dos conflitos, pode-se afirmar com 
precisão cirúrgica, que a paz representa um direito fundamental.

Devem ser garantidos como direitos fundamentais todos aqueles direitos vitais para os quais a garantia é condição necessária da paz: o direito à vida e à integridade pessoal, os direitos civis e políticos, os direitos de liberdade, mas também os direitos sociais à sobrevivência; em resumo todos os direitos em que a ausência de tutela e satisfação se degenera na violência opressiva dos mais fortes ou na revolta dos mais fracos. (FERRAJOLI, 2011, p. 108).

Não obstante a expressa menção no preâmbulo da Declaração Universal dos Direitos Humanos, o direito a uma vida pacífica representa reflexo direto e automático da garantia da dignidade para a pessoa humana, que conforme Cambi (2011, p. 417) consiste na "existência condigna", que não recai somente sobre mera sobrevivência fisiológica, mas sobre o livre desenvolvimento da personalidade do indivíduo enquanto ser.

Assim, o sentimento de paz social compreende um consectário lógico da própria vida digna, uma vez que: “Vislumbra-se, de um certo modo, uma finalidade de coexistência pacífica, em que se fomenta uma maior capacidade dos indivíduos enfrentarem a vida sem desacertos e sem intervenção do Estado". (NETTO, 2015, p. 131)

Vale lembrar que o processo representa o recorte momentâneo de um conflito social. Representa, naquele instante (a lide), um microcosmo com diversos atores e interesses conflitantes, unidos por um interesse comum, qual seja, o término do litígio. Sendo assim, o processo atua como uma lente, que torna mais visível os conflitos que naturalmente emergem da convivência social.

Como afirma Paula (2014, p. 68), a função do processo civil é viabilização da pacificação social por meio da realização da justiça plena, pois não se pode esquecer que o direito processual acaba por vocalizar uma expressão absolutamente essencial e nuclear do processo em si: a realização da justiça. que se desdobra em uma dimensão estruturante do processo ou numa dimensão funcionalista do processo.

Por suposto, a pacificação social pela via processual, decorrente da realização da Justiça, exige que o processo se convole em um efetivo instrumento de terminação de litígios, o que, como demonstra-se no presente estudo, não pode depender exclusivamente da intempestiva sentença de mérito. Nessa linha, o sistema processual deve conter mecanismos de eliminação transversal das lides, por meio da condução da autocomposição de outros meios alternativos 
de prestação jurisdicional. Corrobora esta afirmação, a lição de Luiz Fernando Coelho (2003, p. 190), que alerta que ao jurista caberá continuamente a solução dos conflitos sociais, pois é ele o mensageiro da paz, o portador do direito, o elo entre o direito e a sociedade.

Retomando alguns aspectos da transação em âmbito penal, convém lembrar que, como afirma José Laurindo de Souza Netto (2015, p. 123), acerca da cultura de prevenção dos conflitos: As medidas não dessocializadoras, aplicadas por ocasião da transação, satisfazem à virtual necessidade de pena, refletindo uma resposta antecipada a um provável conflito penal.

Para o autor, a Justiça deve se voltar não apenas para o transgressor, mas também para a vítima, pois por meio da conciliação, é possível a tutela mais eficiente dos interesses envolvidos (do Estado, da vítima e do infrator). Como exemplo, cita o autor que:

[...] a necessidade da realização de uma audiência preliminar, com a possibilidade de acordo entre o envolvido e a vítima (responsável civil), como forma de extinção da punibilidade, introduziu um novo paradigma de Justiça penal baseado no consenso, onde administra-se o conflito, restabelecendo no mundo fático a paz quebrada pelo litígio, passando a vítima a ser sujeito do processo, com status de protagonista da cena judiciária. (NETTO, 2015, p. 129)

Incomensuráveis são os benefícios oriundos da resolução de contendas pela via diplomática, dentre eles, a mitigação das figuras do "vencedor" e do "perdedor" naturalmente surgidas da prolação da sentença. A "derrota processual" gera no perdedor um profundo sentimento de aflição, que não raro o motivará a atuar com mais afinco durante a fase de execução forçada.

De outro vértice, a composição negociada da demanda elimina a figura do "perdedor", pois as partes serão tratadas não mais como adversários, mas como construtores de uma solução benéfica (ou menos maléfica) para ambos. A inclusão das partes no processo produtivo traz como consequência lógica o desaparecimento da figura coatora do Estado-juiz, diminuindo a ingerência estatal e permitindo o desenvolvimento da autonomia privada.

Cabe ressaltar ainda, que em considerável parcela das pretensões resistidas, a "vitória" na contenda não significa a proteção ao direito colimado. É o caso das demandas que versem sobre direitos metaindividuais, a exemplo da tutela do meio-ambiente ou dos direitos do consumidor, pois como explica 
Mancuso (2011, p. 269), ao defender a celebração de acordo em ações civis públicas, que:

[...] haverá casos em que a não celebração do acordo laboraria contra a tutela do interesse metaindividual objetivado, podendo-se figurar caso em que a empresa poluente, reconhecendo ser fundada a pretensão deduzida em ação civil pública, se predisponha a instalar os equipamentos necessários, comprometendo-se a encomendá-los tão logo homologada tal fórmula consensual. Em casos tais, a recusa ao acordo não se justifica, porque nas ações coletivas, o interesse reside menos em "vencer" a causa e, muito mais, em obter, do modo menos oneroso, ou menos impactante, a melhor tutela para o conflito.

Prossegue o autor, afirmando que a solução negociada que se pode conceber numa ação civil pública consiste naquela que, preserva o núcleo essencial do interesse judicializado, porém "flexibiliza em pontos tangenciais ou periféricos, como a fixação de um cronograma razoável para a supressão de uma propaganda enganosa", com intuito de assegurar a máxima efetividade no resultado da demanda (MANCUSO, 2011, p. 269).

\section{A Economia Processual}

Historicamente, o Estado foi avocando para si a atribuição de resolução dos conflitos em sociedade, substituindo gradativamente a autocomposição pela jurisdição oficial. Desse modo, o desenvolvimento de uma complexa estrutura jurisdicional passou a vincular-se ao nível de organização social. Este monopólio acentuou-se a partir da consolidação dos direitos sociais de segunda geração, onde segundo Mancuso (2014, p. 55), a sociedade foi acumulando créditos em face do Estado, para que este pudesse provê-los. Contudo, a assunção deste monopólio de resolução de litígios pelo Estado-juiz, com relação aos conflitos instaurados entre particulares, ou entre estes e a Administração Pública, não foi acompanhada de igual interesse em desenvolver meios capazes de gerir a imensa massa de processos que se avolumou nos escaninhos judiciários.

Ademais, a onda renovatória do acesso à Justiça, na expressão eternizada por Capelletti, experimentada pela sociedade brasileira a partir de 1988, que prometeu ao brasileiro o atendimento aos mais diversos anseios, contribuiu para a o crescimento exponencial dos índices de litigiosidade.

Em outras palavras, o eldorado constitucional deu ao brasileiro a esperança 
dever atendidos todos os seus anseios pela via judiciária, configurando o Estado Democrático de Direito (Art. $1^{\circ}, \mathrm{CF} / 88$ ) em um réu universal, passível de ser acionado a qualquer tempo para assegurar a dignidade da pessoa humana e principalmente os direitos de segunda geração.

Por esse motivo, o Estado pode ser acionado a qualquer instante sob qualquer fundamento, pois mediata ou imediatamente, haverá demonstração de responsabilidade do Estado acerca de violação de alguma garantia constitucional. Ainda que alguma fundamentação possa facilmente ser refutada, o amplo texto constitucional em algum momento dará suporte a mais aventureira das arguições.

Pois bem. Dito que a leitura exacerbada e muitas irrealista do acesso à Justiça, nos dizeres de Mancuso (2014, p. 108), converteu o Judiciário no desaguadouro das mais diversas frustrações da sociedade, resta ao Estado-juiz gerir o contingente de demandas apresentadas em busca do provimento jurisdicional.

Ainda que partindo de uma visão eminentemente instrumental, o provimento jurisdicional (sentença) é um produto, pois se trata do resultado final a ser obtido após uma sucessão de atos preparatórios. Sendo assim, pode-se medir o valor do produto entregue pelo Poder Judiciário (a sentença) aos seus clientes (o jurisdicionado), pelo tempo médio de trabalho direto e indireto dos agentes públicos necessários para obtê-lo.

Conforme dados do anteriormente referido Comunicado ${ }^{\circ} 83$, de 31 de março de 2011, elaborado pelo Instituto de Pesquisas Econômicas Aplicadas - IPEA , o tempo médio total de tramitação do processo de execução fiscal na Justiça Federal é de 8 anos, 2 meses e 9 dias. No que concerne ao tempo médio de investimento de trabalho humano no processo, a tabela abaixo demonstra o trabalho empenhado, de acordo com o grau de envolvimento de cada agente público (BRASIL, 2011):

De acordo com o mesmo estudo, o valor médio cobrado nas ações de execução fiscal corresponde $R \$ 22 \cdot 507,51$. No que concerne ao custo da tramitação de uma ação de execução fiscal na Justiça Federal, o referido estudo mostra que o custo médio de um processo de execução na Justiça Federal, para o ano de 2009, denominado pelo estudo de Processo de Execução Fiscal Médio (PEFM), é de $R \$ 4.685,39$, in verbis:

Tendo em vista os dados sobre o orçamento da Justiça Federal de Primeiro Grau, tem-se que seu custo diário é de $\mathrm{R} \$ 13,5$ milhões e o custo médio do 
processo no ano de 2009 foi de $\mathrm{R} \$ 1,58$ / dia. Logo, o custo médio total provável do Processo de Execução Fiscal Médio (PEFM) é de R\$4.685,39. Quando excluídos os custos com o processamento de embargos e recursos, esse valor é de $\mathrm{R} \$ 4.368,00$. Este último valor é o indicador mais adequado à determinação do custo efetivo do processamento da execução fiscal, na Justiça Federal de Primeiro Grau. (BRASIL, 2011)

O resultado econômico desta análise é de simples silogismo: o Estado (Judiciário) emprega $R \$ 4.685,39$, no intuito de tentar arrecadar (Fazenda) o montante médio de $\mathrm{R} \$ 22.507,51$, o que representa um possível retorno de um ativo igual a $\mathrm{R} \$ 17.822,12$. Tal resulta deriva de um procedimento lógico-formal porque independente de se tratar de Poderes distintos (Judiciário e Executivo), os créditos e débitos envolvidos na operação tem uma origem comum: o Erário.

Ao se confrontar este dado, com o tempo médio de tramitação de uma ação de execução fiscal ( 8 anos, 2 meses e 9 dias), reitera-se a conclusão de alto custo de uma demanda judicial, pois o retorno médio de uma cobrança fiscal não passaria de, aproximadamente, $\mathrm{R} \$ 2.200,00$ por ano.

Convém ressaltar, que tal saldo afirmado nestes exemplos, correspondem às execuções em que o Estado, porventura, seja vencedor da demanda. Como demonstra o mesmo relatório, somente em 33,9\% dos casos a Administração Pública obtém êxito (pagamento integral do débito). Este percentual sobe para $45 \%$, se considerado somente os casos em que há citação válida. Por outro lado, em $27,7 \%$ das ações, opera-se a prescrição da pretensão do Fisco, restando infrutífera a lide intentada.

Em tempo, no estudo aqui utilizado, as ações são dotadas da probabilidade de retorno de valores ao Tesouro, o que permite uma valoração monetária do resultado final. Ocorre que nem todas as demandas tem o Poder Público como credor. Nas hipóteses em que seja o ente público o devedor, o saldo será duplamente negativo: se vencedor, o Estado ainda terá arcado com as despesas da tramitação do processo; se sucumbente, arcará igualmente com tais despesas, acrescidas do valor da condenação.

Os prejuízos diuturnamente suportados pelo Estado, para manutenção de um burocrático e lento sistema judiciário-processual, devem servir de orientação para uma profunda reforma interinstitucional, que não obstante, invista em recursos materiais e tecnológicos, em especial promova a suplantação do modelo demandista atual, para um sistema racional do ponto de 
vista processual e econômico.

Nesse sentido, a solução negociada desponta como meio acessível de resolução de contendas, com reais possibilidades de promover a otimização da máquina judiciária.

Por mais que lute pela celeridade processual e pela efetivação da tutela coletiva, não se pode olvidar que a máquina judiciária possui limites (orçamentários, técnicos, jurídicos, entre outros) e que os julgadores, como todos os seres humanos, estão sujeitos a erros. Nesse cenário, a conciliação mediante concessões recíprocas acerca do direito coletivo em jogo pode ser a melhor solução para o grupo no caso concreto, sobretudo quando houver fundado receio de sucumbência da demanda coletiva. (DONIZETTI; CERQUEIRA, 2010, p. 313).

As vantagens da solução negociada decorrem de uma série de fatores. Em primeiro, a autocomposição permite ao devedor e ao credor, a possibilidade de pactuar termos e condições passíveis de cumprimento para ambos. A pendência de ação judicial acarreta ao réu uma série de infortúnios de toda ordem (certidão positiva), de modo que este, invariavelmente, pode apresentar interesse na transação.

Sem embargo, por boas e conhecidas razões reza a sabedoria popular que "é melhor um mau acordo do que uma boa demanda", ante os fatores imponderáveis e os custos inerentes a toda ação judicial, sem falar nas externalidades negativas, como as restrições diversas, decorrentes da própria pendência da controvérsia e da demora na sua resolução, por exemplo, o retardo na obtenção de financiamento para execução de um projeto ambiental, por conta de ação civil pública em andamento. (MANCUSO, 2011, p. 269).

Em segundo, a participação de ambos os contendores na solução do conflito reflete na cooperação destes com a cumprimento das obrigações avençadas. Segundo as informações do Comunicado ${ }^{\circ} 83$, do IPEA, no universo dos executados que aderem a programas de parcelamento, 64,4\% cumprem integralmente com as obrigações pactuadas, demonstrando assim, que a solução pacífica representa um interessante meio terminativo de litígios, pois aumenta consideravelmente a probabilidade de pagamento por parte do dever, ao passo que diminui os custos com o processo, em decorrência de seu precoce encerramento.

Os programas de parcelamento são eficientes justamente porque permitem a construção dialética da forma de cumprimento da obrigação: o réu deveor 
possui interesse no pagamento do débito, e o Estado por sua vez, interessado no recurso proveniente da obrigação, disponibiliza mecanismos que permitem a adesão flexível do devedor. Assim, quando o devedor constrói a solução compartilhando seus interesses com os do credor, aumentam as chances de efetivo cumprimento da obrigação, conforme demonstrado pelos dados expostos.

Nesse caso, a solução consensual do litígio permite ao Estado a economia de recursos com o tratamento da demanda, uma vez que cada ação em trâmite possui um custo para o Erário. A economia de recursos públicos no tratamento de pluralidade de demandas permitiriao redirecionamento destes recursos para outras finalidades, permitindo assim, melhoria na prestação da função pública (atividade jurisdicional).

Duplamente eficiente é a conciliação quando envolver demanda em que for parte o Estado. Superando eventuais discussões acerca de orçamento próprio de cada Poder, órgão ou entidade, onde por exemplo, determinado município possui seus interesse imediato distinto do interesse imediato do orçamento do tribunal de Justiça do estado federado, deve-se considerar que a finalidade mediata do Erário é a prestação de serviços públicos.

Por esse motivo, quando determinado ógrão ou entidade pertencente à Adminsitração Pública, se utiliza da conciliação para terminar um litígio, há a dupla economia: por se tratar de uma transação processual, há a renuncia mútua, o que trará vantagem para o ente parte, e o Poder Judiário deixa de gerir uma demanda, podendo voltar sua atenção para as demais.

A renúnia mútua, ainda que pelo princípio da indisponibilidade do interesse público imponha determinados limites, será vantajosa quando importar em disposição de pontos tangenciais ou periféricos como multas, prazos ou parcelamento. Nesse caso, o ente flexibiliza o cumprimento da obrigação para obter a satisfação do crédito, enquanto o devedor recebe incentivos para quitação da obrigação.

\section{Conclusão}

Retomando o questionamento feito pelo leigo aos seus colegas juristas, em meados do século passado, que ao ler em um jornal sobre a entrada em vigor o novo código de Processo Civil, e questionando se seria certo que o novo código conseguiria operar esse milagre de transformar a justiça em um mecanismo de 
precisão, percebe-se que passadas décadas a resposta continua a mesma. (CALAMANDREI, 2010, p. 11-12)

O Código de Processo Civil, de per si, não possui o condão de revolucionar o procedimento e de alcançar a tão sonhada efetividade no processo. Evidente que as normas positivas criam obrigações que devem ser seguidas, todavia, talvez o maior mérito do Código seja sua vocação hermeneutêtica de permitir a construção de um novo modelo de jusrisdição, menos estatal e mais compartilhado, on de as partes construam em conjunto a solução mais adequada.

Permite-se com a lei processual vigente, que o conceito de Justiça estatal monopolizada vá, gradualmente, cedendo espaço à chamada jurisdição compartilhada, ensejando uma releitura de temas fundantes como a universalidade da jurisdição e a função instrumental do processo. (MANCUSO, 2014, p. 60). Nessa toada, aproximaria o processo do escopo social principal da jurisdição, qual seja, a pacificação social.

Paralelamente, a inserção da Administração Pública na cultura do perdão e da negociação, tende a se tornar um efetivo instrumento de eficiência (Art. 37, CF/88), pois os métodos autocompisitivos impactam significamente na redução do número de demandas, representando redução do custo com a gestão dos milhares de processos autuados diariamente nos escaninhos judiciários.

\section{REFERÊNCIAS}

BRASIL. Instituto de Pesquisa Econômica Aplicada. Comunicado no 83 de 31 de março de 2011. Custo Unitário do Processo de execução fiscal na Justiça Federal. Disponível em: <http://www.ipea.gov.br/portal/images/stories/ PDFs/comunicado/110331_comunicadoipea83.pdf>. Acesso em: 22 jun. 2015.

CAMBI, E. Neoconstitucionalismo e neoprocessualismo: direitos fundamentais, políticas públicas e protagonismo judiciário. 2. ed. rev. e atual. São Paulo: Revista dos Tribunais, 2011.

CALAMANDREI, Piero. As boas relações entre juízes e advogados. Tradução. Thais Miremis Santefelippo da Silva Amadio. São Paulo: Rideel, 2010. 
COELHO, L. F. Teoria crítica do direito. 3. ed. Belo Horizonte: Del Rey, 2003.

DONIZETTI, E; CERQUEIRA, M. M. Curso de processo coletivo: contém jurisprudência temática e índice alfabético por assunto. São Paulo: Atlas, 2010.

DINAMARCO, C. R. Teoria geral do novo processo civil. São Paulo: Malheiros, 2016

Manual das pequenas causas. São Paulo: Revista dos Tribunais, 1986.

FERRAJOLI, L. Por uma teoria dos direitos fundamentais. Trad. Alexandre Salim, Alfredo Copetti Neto, Daniela Cadermatori, Hermes Zaneti Júnior, Sérgio Cadermatori. Porto Alegre: Livraria do Advogado, 2011.

MANCUSO, R. de C. Ação civil pública: em defesa do meio ambiente, do patrimônio cultural e dos consumidores. 12. ed. rev., atual. e ampl. São Paulo: Revista dos Tribunais, 2011.

Interesses Difusos. 8. ed. rev. atual. e ampl. São Paulo: Revista dos Tribunais, 2013.

MARINONI, L. G.; ARENHART, S. C.; MITIDIERO, D. Novo código de processo civil comentado. São Paulo: Revista dos Tribunais, 2015.

MEDINA, J. M. G. Novo código de processo civil comentado: com remissões e notas comparativas ao CPC/1973. São Paulo: Revista dos Tribunais, 2015.

Direito processual civil moderno. 2. ed. rev., atual. e ampl. São Paulo: Revista dos Tribunais, 2016.

Parte geral e processo de conhecimento. 3. ed. rev., atual. e ampl. São Paulo: Revista dos Tribunais, 2013.

MOREIRA, J. C. B. O novo processo civil brasileiro. 27. ed. rev. atual. Rio de Janeiro: Forense, 2008.

NETTO, J. L. de S. Processo penal: modificações na lei dos juizados especiais. 2. ed. Curitiba: Juruá, 2015. 
PAULA, J. L. M. de. Democracia e jurisdição. Curitiba: JM, 2014.

Uma visão crítica da jurisdição civil. Leme: LED. 1999.

A jurisdição como elemento de inclusão social: revitalizando as regras do jogo democrático. São Paulo: Monole, 2002.

WOLKMER, A. C. Elementos para uma crítica do estado. Porto Alegre: S. Fabris, 1990. 